\title{
Herança da resistência à mancha-foliar de feosféria em milho(1)
}

\author{
Diego Girardi Pegoraro (2), José Fernandes Barbosa Neto ${ }^{(3)}$, Fábio Kessler Dal Soglio(3), \\ Elton Vacaro(4), Claudio Natalino Nuss ${ }^{(4)}$ e Léo Duc Haa Conceição(5)
}

\begin{abstract}
Resumo - A mancha-foliar de feosféria tem causado expressiva redução no rendimento de grãos de milho, no Brasil, principalmente, em decorrência da crescente amplitude da data de semeadura, conjugada com o uso de áreas irrigadas e de plantio direto. É importante o desenvolvimento de genótipos resistentes a essa moléstia; porém a realização de uma seleção eficiente depende do entendimento da variabilidade genética e da herança da resistência. Com o objetivo de determinar a capacidade combinatória e o modo de herança do caráter, foram cruzadas sete linhagens de milho, para a realização das análises dialélica e média de gerações. Os experimentos foram conduzidos no Município de Xanxerê, SC, sendo avaliada a porcentagem de tecido foliar afetado pela moléstia 30 dias após o florescimento. Os genótipos apresentaram amplitude de $4,3 \%$ a $67,0 \%$ de área foliar afetada pela moléstia, na qual a linhagem LA06 e seus híbridos demonstraram elevada resistência. Os resultados indicaram que a seleção de genótipos resistentes à feosféria pode ser realizada com sucesso em programas de melhoramento do milho, visto que a manifestação do caráter é controlada por, pelo menos, dois genes independentes e com uma efetiva participação de efeitos aditivos.
\end{abstract}

Termos para indexação: Phaeosphaeria maydis, teste de progênie, variação genética, melhoramento vegetal.

\section{Inheritance of the resistance to phaeosphaeria leaf spot in maize}

\begin{abstract}
Phaeosphaeria leaf spot (PLS) has caused an expressive reduction in the corn grain yield in Brazil. The increment in sowing date amplitude, conjugated with the use of irrigated areas and zero tillage, had major contribution in the increase of phaeosphaeria leaf spot (PLS) incidence and severity. For this reason, it is important to develop resistant genotypes to this disease; however, an efficient selection depends upon the understanding of the genetic variability and inheritance of the resistance. Aiming to determine combining ability and the mode of inheritance for PLS, seven corn inbreds were crossed for diallel and generation mean analysis. The experiments were conducted in Xanxerê, SC. Percentage of foliar area affected by the disease was evaluated 30 days after flowering. The genotypes presented amplitude of $4.3 \%$ to $67.0 \%$ of foliar area affected by PLS. The LA06 and its hybrids showed high level of resistance. Results indicated that selection for PLS resistant genotypes could be successfully accomplished in corn breeding programs. At least two major independent genes were identified with a preponderant participation of addictive effects in the inheritance of the trait.
\end{abstract}

Index terms: Phaeosphaeria maydis, progeny testing, genetic variation, plant breeding.

(1) Aceito para publicação em 27 de dezembro de 2000. Extraído da Dissertação de Mestrado apresentada pelo primeiro autor à Universidade Federal do Rio Grande do Sul (UFRGS), Faculdade de Agronomia (FA), Porto Alegre, RS.

${ }^{(2)}$ Fundação Pró-Sementes de Apoio à Pesquisa, Rua Diogo de Oliveira 640, CEP 99025-130 Passo Fundo, RS. E-mail: dgpegoraro@hotmail.com

(3)UFRGS, Faculdade de Agronomia, Av. Bento Gonçalves 7712, Caixa Postal 776, CEP 91501-970 Porto Alegre, RS. E-mail: jfbn@vortex.ufrgs.br, fabiods@vortex.ufrgs.br

(4)Empresa Agroeste Sementes Ltda., Rua Antônio Vacaro, 130, CEP 89820-000 Xanxerê, SC. E-mail: evacaro@yahoo.com

${ }^{(5)}$ UFRGS, Faculdade de Agronomia, Bolsista do PIBIC/CNPq,

\section{Introdução}

O dano causado por moléstias na cultura do milho (Zea mays L.) vem aumentando no sul do Brasil com o incremento na amplitude da data de semeadura, conjugado com o uso de áreas irrigadas e de plantio direto. Entre estas moléstias, a mancha-foliar de feosféria tem causado expressiva redução no rendimento de grãos em cultivos tardios nas regiões produtoras de milho (Fernandes \& Oliveira, 1997). Essa moléstia era considerada como secundária, na cultura do milho, por apresentar sintomas apenas na parte final do ciclo (Balmer \& Pereira, 1987). 
No entanto, Fantin (1994) identificou sintomas em plantas no estádio vegetativo, quando o ambiente favoreceu o desenvolvimento do patógeno. Essa moléstia tem aumentado em incidência e severidade praticamente em todas as regiões brasileiras (Fernandes \& Oliveira, 1997). Entre as manchas foliares, a feosféria é a mais severa nos estados do Paraná (Fantin, 1994) e Rio Grande do Sul (Recomendações..., 1998).

O agente causal da moléstia feosféria é o fungo Phaeosphaeria maydis (P. Henn.) Rane, Payak e Renfro (sinônimo Sphaerulina maydis), cujo estádio anamórfico é Phillosticta sp. (Reis \& Casa, 1996; Fernandes \& Oliveira, 1997). Os sintomas da moléstia iniciam, em geral, com pequenas manchas levemente cloróticas nas folhas, redondas a oblongas com 0,3 até $2,0 \mathrm{~cm}$. No início, as lesões são aquosas, de coloração verde-claro, e com os bordos bem definidos de cor pardo-escuro (Reis \& Casa, 1996; Fernandes \& Oliveira, 1997). Geralmente, os sintomas aparecem primeiro nas folhas inferiores, progredindo rapidamente para o ápice da planta.

É importante o desenvolvimento de genótipos resistentes à feosféria para a prevenção de perdas no rendimento de grãos; mas a realização de uma seleção eficiente depende do entendimento da herança da resistência e da variabilidade genética existente. Tem sido observada elevada variabilidade genética quanto à resistência à mancha-foliar de feosféria em genótipos comerciais de milho brasileiro (Sawazaki et al., 1997; Brasil \& Carvalho, 1998) e no germoplasma americano (Carson, 1999).

Sobre a herança da resistência a essa moléstia, as informações são escassas. Carson et al. (1996), utilizando marcadores moleculares, identificaram regiões cromossômicas associadas à resistência à feosféria em linhagens recombinantes de milho, sugerindo a existência de dominância parcial. Das et al. (1989a, 1989b) também indicaram que os efeitos de dominância eram mais importantes do que os de aditividade para a resistência à feosféria.

O objetivo deste trabalho foi avaliar a capacidade combinatória de linhagens de milho em relação ao caráter resistência à mancha-foliar de feosféria, identificar genótipos resistentes, e estimar sua herdabilidade, ação gênica e número de genes envolvidos na herança do caráter.

\section{Material e Métodos}

O experimento foi realizado no ano agrícola de 1998/99, na Estação Experimental da Empresa Agroeste Sementes Ltda., situada no Município de Xanxerê, SC, a uma altitude de $600 \mathrm{~m}$. Em 1997/98 sete linhagens de milho foram selecionadas de acordo com o nível de resistência observado. As linhagens LA06, LA27 e LA30 foram classificadas como resistentes, as linhagens LA67 e LA99 como suscetíveis, e as linhagens LA55 e LA45 como intermediárias, de acordo com a porcentagem de área foliar afetada por feosféria. $\mathrm{O}$ estudo de herança realizado neste trabalho empregou duas análises quantitativas diferenciadas: análise dialélica e média de gerações.

Para a análise dialélica, sete linhagens foram cruzadas entre si no ano de 1998, em campo de inverno, no Município de Campo Verde, MT; entretanto, a linhagem LA27 foi retirada da análise pela impossibilidade de obtenção de todos os seus cruzamentos. Os 21 tratamentos (15 híbridos e seis genitores) foram reunidos em um delineamento experimental de blocos casualizados, com três repetições. A semeadura foi realizada em 5/11/1998. Foram aplicados $500 \mathrm{~kg} / \mathrm{ha}$ da fórmula 5-20-20, e em cobertura $100 \mathrm{~kg} / \mathrm{ha}$ de N, no estádio de crescimento V6 (Ritchie et al., 1999). Cada parcela experimental era constituída por uma fileira de $5 \mathrm{~m}$ de comprimento. As parcelas foram plantadas a espaços de $0,80 \mathrm{~m}$, e as plantas dentro da linha, em 0,25 m. Quando necessário, foi realizada irrigação com o auxílio de aspersores. A avaliação visual da porcentagem de área foliar afetada pela mancha de feosféria levou em conta a média da parcela, e foi realizada com base na infestação natural do fungo, 30 dias após o florescimento, correspondendo ao estádio de crescimento R5 (Ritchie et al., 1999).

Os dados foram submetidos à análise de variância conforme o modelo:

$X_{\mathrm{ik}}=\mu+\rho_{\mathrm{k}}+\alpha_{\mathrm{i}}+\varepsilon_{\mathrm{ik}}$, onde:

$\mathrm{X}_{\mathrm{ik}}$ é a porcentagem de área foliar atacada por feosféria no genótipo i, e repetição $\mathrm{k} ; \mu$, a média geral; $\rho_{\mathrm{k}}$, o efeito aleatório da repetição $\mathrm{k}$; $\alpha_{\mathrm{i}}$, o efeito fixo do genótipo $\mathrm{i}$; $\varepsilon_{\mathrm{ik}}$, o erro $\sim \mathrm{N}\left(0, \sigma^{2}\right)$.

Posteriormente, a soma de quadrados do efeito dos genótipos foi decomposta em capacidade geral de combinação (CGC) e capacidade específica de combinação (CEC). Nessa análise foi adotado o método 2, modelo fixo do sistema de análise dialélica proposto por Griffing (1956), o qual considera os genitores e apenas um conjunto de $\mathrm{F}_{1}$, excluindo os recíprocos. $\mathrm{O}$ modelo estatísti- 
co usado foi:

$X_{i j k}=\mu+g_{i}+g_{j}+s_{i j}+\varepsilon_{i j k}$,

onde:

$\mathrm{X}_{\mathrm{ijk}}$ é a porcentagem de área foliar atacada por feosféria no cruzamento das linhagens genitoras i e j, na repetição $\mathrm{k}$; $\mu$, a média geral; $\mathrm{g}_{\mathrm{i}}, \mathrm{g}_{\mathrm{j}}$, os efeitos de CGC correspondentes aos genitores i e $\mathrm{j}$, respectivamente; $\mathrm{s}_{\mathrm{ij}}$, o efeito de CEC no cruzamento entre as linhagens $\mathrm{i}$ e j; $\varepsilon_{\mathrm{ijk}}$, o erro $\sim \mathrm{N}\left(0, \sigma^{2}\right)$.

$\mathrm{Na}$ análise da média de gerações, foram incluídas duas linhagens resistentes (LA06 e LA27) e uma suscetível (LA67), e realizaram-se os seguintes cruzamentos: resistente 1 (LA06) x suscetível (LA67), resistente 2 (LA27) x suscetível (LA67), e resistente 1 (LA06) x resistente 2 (LA27). Essas linhagens foram selecionadas pelo nível de resistência apresentado, e pelo fato de a empresa já possuir os híbridos $F_{1}$, facilitando a obtenção da geração $F_{2}$ no campo de inverno. No campo de inverno os híbridos $\mathrm{F}_{1}$ foram semeados em 1998, e depois autofecundados, para a obtenção da geração segregante $\mathrm{F}_{2}$.

$\mathrm{O}$ experimento com as gerações $\mathrm{P}_{1}, \mathrm{P}_{2}, \mathrm{~F}_{1}$ e $\mathrm{F}_{2}$ foi conduzido em um delineamento experimental de parcelas subdivididas, com duas repetições, nas quais a parcela principal foi constituída pelo cruzamento, e a subparcela, pela geração dentro de cada cruzamento. Os pais e a progênie $\mathrm{F}_{1}$ foram semeados em duas e três fileiras por repetição, respectivamente. Na geração $\mathrm{F}_{2}$, o número de linhas variou de acordo com o número de sementes disponíveis, sendo de 14 linhas por repetição para o cruzamento LA06 x LA67, 11, para LA27 x LA67, e oito, para LA06 x LA27. As fileiras possuíam $5 \mathrm{~m}$ de comprimento, com espaçamento de $0,80 \times 0,50 \mathrm{~m}$ e duas plantas por cova. A semeadura e o manejo agronômico do experimento foi similar ao empregado na análise dialélica. A avaliação da severidade de feosféria foi realizada da mesma maneira que o experimento da análise dialélica, mas as plantas foram analisadas individualmente.

Os dados de porcentagem de área foliar atacada pela feosféria foram submetidos à análise de variância, usando o modelo:

$\mathrm{X}_{\mathrm{ijk}}=\mu+\beta_{\mathrm{k}}+\pi_{\mathrm{i}}+(\mathrm{g} / \pi)_{\mathrm{ij}}+\varepsilon_{\mathrm{ijk}}$, onde:

$\mathrm{X}_{\mathrm{ijk}}$ é a porcentagem de área foliar atacada por feosféria no cruzamento i, geração $\mathrm{j}$, e repetição $\mathrm{k}$; $\mu$, a média ge$\mathrm{ral} ; \beta_{\mathrm{k}}$, o efeito aleatório da repetição $\mathrm{k} ; \pi_{\mathrm{i}}$, o efeito fixo de população $i ; g / \pi_{i j}$, o efeito fixo da geração $j$ dentro da população i; $\varepsilon_{\mathrm{ijk}}, \mathrm{o}$ erro $\sim \mathrm{N}\left(0, \sigma^{2}\right)$.
As hipóteses de nulidade testadas através do teste $\mathrm{F}$ foram:

$\mathrm{H}_{01}: \beta_{\mathrm{k}}=0$ e $\mathrm{H}_{02}: \mathrm{g} / \pi_{\mathrm{ij}}=0$.

A herdabilidade foi estimada com base na decomposição da variância fenotípica, segundo método proposto por Allard (1960). Os parâmetros genéticos média ([m]), aditividade ([a]) e dominância ([d]) foram estimados em cada cruzamento, pela análise da média de gerações, utilizando o método dos quadrados mínimos esperados (Mather $\&$ Jinks, 1982). A estimativa foi seguida de teste de escala em conjunto, comparando as médias observadas com as esperadas pelo teste de qui-quadrado $\left(\chi^{2}\right)$. O número de gerações disponíveis em cada cruzamento não permitiu a inclusão dos efeitos de epistasia no modelo. O número de genes foi estimado a partir das freqüências obtidas em cada geração. A hipótese de segregação da geração $F_{2}$ foi verificada pelo teste do $\chi^{2}$.

\section{Resultados e Discussão}

Os genótipos apresentaram diferenças significativas quanto à porcentagem de área foliar afetada pela mancha-de-feosféria, sugerindo, assim, a presença de elevada variabilidade genética do caráter (Tabela 1). As linhagens LA06 e LA30 demonstraram menor área foliar afetada pela moléstia, e foram classificadas como resistentes. As linhagens LA67, LA99 e LA45 apresentaram suscetibilidade ao fungo, enquanto a LA55 teve comportamento intermediário. Nos híbridos avaliados na análise dialélica, a porcentagem de área foliar afetada variou de 11 a $67 \%$, com predominância de valores no sentido da suscetibilidade. Nos cruzamentos envolvendo as linhagens classificadas como resistentes, apenas os híbridos em que houve a participação da linhagem resistente LA06 evidenciaram menor área foliar afetada.

O fator genótipo foi decomposto em capacidade geral e específica de combinação, e ambas foram significativas estatisticamente (Griffing, 1956). O modelo utilizado na análise (fixo) não permitiu a estimação das variâncias de aditividade e de dominância; entretanto, de acordo com os valores obtidos, referentes aos quadrados médios de CGC (3558) e de CEC (91), é possível sugerir a maior importância dos efeitos de aditividade em relação aos não-aditivos. Essa variância reduzida para a CEC reflete a grande concentração de híbridos com valo- 
res elevados de área foliar afetada. De maneira geral, os efeitos de aditividade têm sido indicados como os mais significativos na herança dos principais caracteres de importância agronômica em milho (Vasal et al., 1992). Esse fato é de extrema importância no melhoramento genético de plantas, uma vez que apenas os efeitos de aditividade são transmitidos aos descendentes. Assim sendo, os resultados observados na análise permitem prever que a herdabilidade no sentido restrito deve ser de média a alta em relação à resistência à feosféria, o que indica que genótipos resistentes possam ser eficientemente selecionados em populações segregantes.

A seleção dos genitores do bloco de cruzamento é um aspecto fundamental em um programa de melhoramento. A estimação dos efeitos de CGC e CEC demonstraram valores negativos de CGC nas linhagens LA06 e LA30 (Tabela 2). Os valores negativos indicam a contribuição dos genitores no sentido da resistência; conseqüentemente, esses genótipos de- vem ser empregados preferencialmente em programas de melhoramento que visem ao desenvolvimento de variedades resistentes à feosféria. Os demais genitores avaliados apresentaram valores positivos de CGC, o que evidencia deficiências para o seu uso em blocos de cruzamento. Os efeitos estimados de CEC variaram de $-9,98$ até 6,94. Os cruzamentos em que a linhagem resistente LA06 participou tiveram os menores valores de CEC, enquanto o mesmo não aconteceu com a linhagem LA30, que também apresentou valor negativo de CGC. Dessa forma, a linhagem LA06 possui elevado potencial para incrementar a resistência à feosféria em milho e deve estar presente em programas de melhoramento. A linhagem LA30 pode ser genitora em cruzamentos específicos para a produção de híbridos ou populações de polinização aberta com resistência à feosféria.

Para complementar os resultados obtidos na análise dialélica, três cruzamentos foram avaliados com

Tabela 1. Média de porcentagem da área foliar afetada pela feosféria em seis linhagens de milho e em seus 15 híbridos. Xanxerê, SC, 1998/99(1).

\begin{tabular}{llllllll}
\hline Pais & \multicolumn{5}{c}{ Média dos cruzamentos } & \multirow{2}{*}{ Média $\mathrm{F}_{1}$} \\
\cline { 2 - 6 } & LA06 & LA30 & LA55 & LA45 & LA67 & LA99 & \\
\hline LA06 & $4,3 \mathrm{~h}$ & $11,0 \mathrm{gh}$ & $25,0 \mathrm{fgh}$ & $16,0 \mathrm{fgh}$ & $29,0 \mathrm{defg}$ & $23,0 \mathrm{fgh}$ & 20,8 \\
LA30 & & $23,0 \mathrm{fgh}$ & $42,0 \mathrm{bcdef}$ & $43,0 \mathrm{bcdef}$ & $46,0 \mathrm{abcde}$ & $50,0 \mathrm{abcd}$ & 38,4 \\
LA55 & & & $38,0 \mathrm{cdef}$ & $51,0 \mathrm{abcd}$ & $60,0 \mathrm{ab}$ & $55,0 \mathrm{abc}$ & 46,6 \\
LA45 & & & $55,0 \mathrm{abc}$ & $67,0 \mathrm{a}$ & $48,0 \mathrm{abcd}$ & 45,0 \\
LA67 & & & & $62,0 \mathrm{ab}$ & $64,0 \mathrm{ab}$ & 53,2 \\
LA99 & & & & $61,0 \mathrm{ab}$ & 48,0 \\
\hline
\end{tabular}

${ }^{(1)}$ Médias seguidas de mesma letra não diferem entre si pelo teste de Tukey a 5\% de probabilidade.

Tabela 2. Efeitos de capacidade geral $\left(\mathrm{g}_{\mathrm{i}}\right)$ e específica de combinação $\left(\mathrm{s}_{\mathrm{ij}}\right)$ para a porcentagem da área foliar afetada pela feosféria em seis linhagens de milho em seus 15 híbridos. Xanxerê, SC, 1998/99.

\begin{tabular}{lccrrrrr}
\hline Pais & \multicolumn{5}{c}{$\mathrm{S}_{\mathrm{ij}}$} & \multicolumn{2}{c}{$\mathrm{g}_{\mathrm{i}}$} \\
\cline { 2 - 6 } & LA06 & LA30 & LA55 & LA45 & LA67 & \multicolumn{1}{c}{ LA99 } & \\
\hline LA06 & 6,19 & $-1,63$ & 2,87 & $-9,98$ & $-2,56$ & $-5,81$ & $-21,73$ \\
LA30 & & $-5,10$ & 5,40 & 2,54 & $-0,71$ & 6,71 & $-6,92$ \\
LA55 & & & $-7,43$ & 1,04 & 4,46 & 3,21 & 1,92 \\
LA45 & & & 1,52 & 6,94 & $-8,31$ & 6,11 \\
LA67 & & & & $-0,23$ & 1,77 & 12,02 \\
LA99 & & & & & $-0,89$ & 8,60 \\
\hline Média & & & & & & 42,08 \\
\hline
\end{tabular}


suas gerações $F_{1}$ e $F_{2}$ pelo método da média das gerações. Esse procedimento expressa a média das gerações de genitores homozigotos em termos genéti$\cos$, possibilitando a estimação de efeitos de aditividade, de dominância e de epistasia (Dudley, 1997). A análise da variância dos dados do experimento não detectou diferenças significativas entre as repetições, porém apresentou diferenças significativas entre as gerações dentro das populações. Com isso, os indivíduos de cada repetição foram considerados conjuntamente, para a estimação dos parâmetros genéticos. A distribuição de freqüência foi contínua em todos os cruzamentos (Figura 1), e isto evidencia a influência do ambiente na manifestação do caráter porcentagem da área foliar afetada pela mancha-de-feosféria. Esse efeito foi particularmente pronunciado na linhagem suscetível LA67. De maneira distinta, a variância observada nas linha-
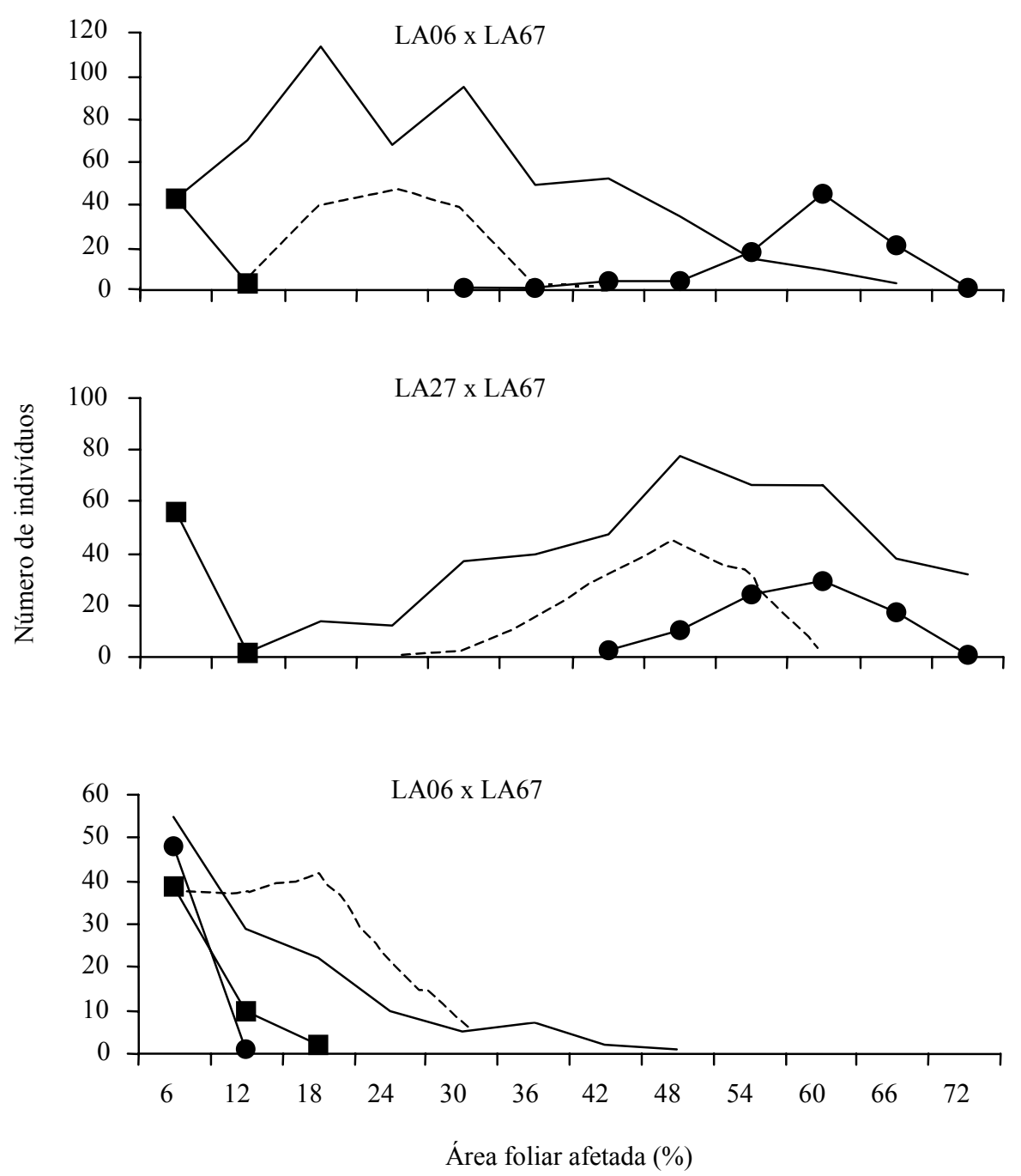

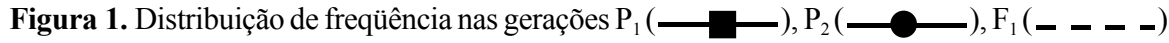
e $\mathrm{F}_{2}$ (ـ ) quanto ao caráter porcentagem de tecido foliar afetado pela feosféria, em três cruzamentos distintos, em milho. Xanxerê, SC, 1998/99. 
gens resistentes (LA06 e LA27) foi reduzida, provavelmente em virtude do truncamento da distribuição no valor $0 \%$. No cruzamento LA06 x LA67, ficou evidenciado que as médias das gerações $\mathrm{F}_{1}$ e $\mathrm{F}_{2}$ estiveram situadas no sentido do pai resistente, o que sugere a presença de dominância no sentido da resistência. No cruzamento LA27 x LA67, as médias das gerações $F_{1}$ e $F_{2}$ ficaram mais próximas do pai suscetível, indicando, assim, dominância no sentido contrário ao detectado na combinação anterior. No cruzamento envolvendo os pais resistentes (LA06 x LA27), as médias da $F_{1}$ e da $F_{2}$ foram superiores (mais suscetíveis) à média dos pais. A segregação transgressiva obtida nesse cruzamento é um indicativo da presença de genes complementares do caráter resistência à feosféria nos pais, e um deles é dominante quanto à resistência, e o outro, recessivo. Este fato é de grande importância, uma vez que indica a possibilidade de selecionar novas linhagens com elevada resistência à feosféria a partir do cruzamento dessas duas linhagens resistentes.

Em todos os cruzamentos foi verificada variabilidade genética quanto à resistência à feosféria (Tabela 3). Os valores estimados de herdabilidade foram elevados, e sugerem a possibilidade de obtenção de ganhos genéticos mediante a seleção fenotípica de indivíduos resistentes à feosféria em gerações segregantes. No entanto, a herdabilidade calculada não separou as variâncias de aditividade e de dominância, uma vez que a ausência de retrocruzamentos impediu estimar a variância aditiva. Além do mais, o efeito da interação genótipo $\mathrm{x}$ ambiente não foi avaliado, pois o experimento foi conduzido em apenas um ambiente. Segundo Allard (1960), a herdabilidade não é propriedade de um caráter, mas

Tabela 3. Variância fenotípica $\left(\sigma_{\mathrm{P}}^{2}\right)$, variância genética $\left(\sigma_{\mathrm{G}}^{2}\right)$, variância de ambiente $\left(\sigma_{\mathrm{E}}^{2}\right)$ e herdabilidade $\left(\mathrm{h}_{\mathrm{a}}^{2}\right)$ em cruzamentos entre linhagens de milho, quanto ao caráter porcentagem de tecido foliar afetado pela feosféria. Xanxerê, SC, 1998/99.

\begin{tabular}{lrrcc}
\hline Cruzamentos & \multicolumn{1}{c}{$\sigma_{\mathrm{P}}^{2}$} & \multicolumn{1}{c}{$\sigma_{\mathrm{G}}^{2}$} & $\sigma_{\mathrm{E}}^{2}$ & $\mathrm{~h}_{\mathrm{a}}^{2}$ \\
\hline LA06 x LA67 & 180,4 & $153,1 \pm 23,5$ & 20,6 & 0,85 \\
LA27 x LA67 & 193,7 & $163,3 \pm 28,1$ & 30,4 & 0,84 \\
LA06 x LA27 & 95,6 & $75,4 \pm 24,6$ & 20,2 & 0,79 \\
\hline
\end{tabular}

da condição da população e das condições de ambiente. Desta forma, os valores apresentados neste trabalho devem ser considerados como indicativos de herdabilidade favorável para o desenvolvimento de genótipos de milho resistentes à feosféria.

$\mathrm{O}$ modelo aditivo-dominante, composto pelos parâmetros [m], [a] e [d], não foi adequado para explicar as bases genéticas da resistência à feosféria nos cruzamentos LA27 x LA67 e LA06 x LA27, o que sugere que os efeitos de epistasia possuem importância na herança da resistência à feosféria (Tabela 4). Por outro lado, no cruzamento LA06 x LA67 esse modelo foi adequado, indicando, assim, que os efeitos de epistasia não foram importantes para esse caso. A resistência à feosféria é inversamente proporcional aos valores da área foliar afetada, e valores negativos indicam maior resistência. Os efeitos de dominância foram significativos em todos os cruzamentos, porém os efeitos aditivos foram superiores nos cruzamentos LA06 x LA67 e LA27 x LA67. No LA06 x LA27, os efeitos de dominância foram maiores do que os de aditividade, com valores positivos, ou seja, em direção à suscetibilidade. De maneira geral, os resultados da média das gerações foram consistentes com os obtidos na análise dialélica. Os efeitos de aditividade demonstraram ser da maior significância na determinação do modo de herança da resistência à feosféria, porém, com desvios de dominância e epistasia também participando na manifestação fenotípica do caráter.

Com base na freqüência dos indivíduos $F_{2}$, foi desenvolvida a hipótese de três genes maiores governando o caráter resistência à feosféria nos genótipos de milho estudados. A Tabela 5 apresenta a inferência dos prováveis genótipos dos pais empregados no estudo, assim como os testes de $\chi^{2}$ para a verificação da adequação da hipótese de segregação. Quanto à construção dos genótipos, foi assumida a presença de dominância parcial e epistasia, conforme indicado pela análise da média das gerações. Os alelos representados com letras maiúsculas indicam resistência, e as letras minúsculas indicam suscetibilidade, não considerando a direção da dominância. Da mesma forma, a presença de genes complementares foi incluída na construção dos genótipos. Os resultados obtidos com a análise sustentaram a hipótese de três genes maiores governan- 
Tabela 4. Valores estimados dos parâmetros média (m), atividade (a) e dominância (d), e teste de escala $\left(\chi^{2}\right)$ em cruzamentos entre linhagens de milho quanto ao caráter porcentagem de tecido foliar afetado pela feosféria. Xanxerê, SC, 1998/99.

\begin{tabular}{lrrrc}
\hline Cruzamentos & \multicolumn{1}{c}{$\mathrm{m}$} & $\mathrm{a}$ & $\mathrm{d}$ & $\chi^{2}$ \\
\hline LA06 x LA67 & $29,58 \pm 0,38$ & $-26,66 \pm 0,39$ & $-8,25 \pm 0,60$ & 2,48 \\
LA27 x LA67 & $30,47 \pm 0,36$ & $-26,76 \pm 0,37$ & $17,22 \pm 0,69$ & $182,78^{(1)}$ \\
LA06 x LA27 & $3,91 \pm 0,29$ & $1,37 \pm 0,28$ & $9,39 \pm 0,61$ & 18,08 \\
\hline
\end{tabular}

${ }^{(1)}$ Cruzamento não ajustado ao modelo de três parâmetros por teste de qui-quadrado a $5 \%$ de probabilidade.

Tabela 5. Número de genes estimados quanto a resistência à feosféria, em três cruzamentos em milho. Xanxerê, SC, 1998/99.

\begin{tabular}{lcccccc}
\hline Cruzamentos & \multicolumn{2}{c}{ Genes $^{(1)}$} & & \multicolumn{2}{c}{ Proporção } & \multirow{2}{*}{$\chi^{2}$} \\
\cline { 2 - 3 } & Pai 1 & Pai 2 & & Esperada & Obtida & \\
\hline LA06 x LA67 & AABBcc & aabbcc & & $1: 8: 6: 1$ & $42: 249: 229: 27$ & \\
LA27 x LA67 & aaBBCC & aabbcc & & $1: 8: 6: 1$ & $28: 202: 170: 32$ & 2,3 \\
LA06 x LA27 & AABBcc & aaBBCC & & $15: 1$ & $121: 10$ & 0,4 \\
\hline
\end{tabular}

${ }^{(1)}$ Letra maiúscula: resistência; letra minúscula: suscetibilidade. (2)Proporções obtida e esperada são diferentes significativamente pelo teste de qui-quadrado a $5 \%$ de probabilidade.

do o caráter resistência à feosféria. Por outro lado, o fato de no cruzamento LA27 x LA67 a classe do pai resistente não ter sido totalmente recuperada na geração $F_{2}$ sugere outros genes de menor efeito atuando na herança do caráter.

Com base nos resultados obtidos, a identificação de genótipos resistentes à feosféria pode ser realizada com sucesso em programas de melhoramento de milho que visem à produção de variedades sintéticas ou híbridas, uma vez que sua herdabilidade parece ser de média a alta, e a variância dos genótipos resistentes foi reduzida. Esses fatores conjuntamente podem garantir a seleção fenotípica eficiente de genótipos resistentes. Pelo menos dois genes maiores foram identificados nos cruzamentos realizados, e as duas análises quantitativas sugeriram grande participação dos efeitos de aditividade na herança do caráter. No melhoramento de populações, a utilização da seleção massal fenotípica poderá proporcionar ganhos para a resistência à feosféria. Da mesma forma, no desenvolvimento de linhagens, a seleção em $\mathrm{S}_{2}$ ou $\mathrm{S}_{3}$ é viável, e deverão ser feitas avaliações posteriores em gerações com maior homozigose $\left(\mathrm{S}_{4}\right.$, $\mathrm{S}_{5}$ ou $\mathrm{S}_{6}$ ) com o objetivo de selecionar genes com menor efeito no caráter.

\section{Conclusões}

1. Há variabilidade genética para resistência à feosféria em milho.

2. Os efeitos de aditividade são da maior importância na herança do caráter, resistência à feosféria, porém, os efeitos de dominância e epistasia também têm participação.

3. Há evidências da participação de pelo menos dois genes independentes na manifestação do caráter resistência à feosféria, nas linhagens avaliadas.

4. As linhagens LA06, LA27 e LA30 devem ser empregadas em programas de melhoramento de milho com o objetivo de incrementar a resistência à mancha-foliar de feosféria, em milho.

\section{Referências}

ALLARD, R. W. Principles of plant breeding. 3. ed. New York: J. Wiley, 1960. 485 p.

BALMER, E.; PEREIRA, O. A. P. Moléstias no milho. In: PATERNIANI, E.; VIÉGAS, G. P. (Ed.). Melhoramento e produção de milho. 2. ed. Campinas: Fundação Cargill, 1987. p. 597-634.

Pesq. agropec. bras., Brasília, v. 37, n. 3, p. 329-336, mar. 2002 
BRASIL, E. M.; CARVALHO, Y. Comportamento de híbridos de milho em relação a Phaeosphaeria maydis em diferentes épocas de plantio. Pesquisa Agropecuária Brasileira, Brasília, v. 33, n. 12, p. 1977-1981, dez. 1998.

CARSON, M. L. Vulnerability of U.S. maize germ plasm to Phaeosphaeria leaf spot. Plant Disease, Saint Paul, v. 83, p. 462-464, 1999.

CARSON, M. L.; STUBER, C. W.; SENIOR, M. L. Identification of quantitative trait loci (QTLs) for resistance to foliar diseases in a mapping population of recombinant inbred (RI) lines of maize. Phytopathology, Saint Paul, v. 86, n. 9 , p. 89 , 1996. Supplement.

DAS, S. N.; PRODHAN, H. S.; KAISER, S. A. K. M. Further studies on the inheritance of resistance to Phaeosphaeria leaf spot of maize. Indian Journal of Mycological Research, Calcutta, v. 27, p. 127-130, 1989a.

DAS, S. N.; SINHAMAHAPATRA, S. P.; BASAK, S. L. Inheritance of resistance to Phaeosphaeria leaf spot of maize. Annual Agricultural Research, Nadia, v. 10, p. 182-184, 1989 b.

DUDLEY, J. W. Quantitative genetics and plant breeding. Advances in Agronomy, San Diego, v. 59, p. 1-23, 1997.

FANTIN, G. M. Mancha de Phaeosphaeria, moléstia do milho que vem aumentando a sua importância. Biológico, São Paulo, v. 56, n. 1/2, p. 39, jan./dez. 1994.

Pesq. agropec. bras., Brasília, v. 37, n. 3, p. 329-336, mar. 2002
FERNANDES, F. T.; OLIVEIRA, E. Principais moléstias na cultura do milho. Sete Lagoas: Embrapa-CNPMS, 1997. $80 \mathrm{p}$.

GRIFFING, B. Concept of general and specific combining ability in telation to crossing systems. Australian Journal of Biological Sciences, Collingwood, v. 9, p. 463-493, 1956.

MATHER, K.; JINKS, J. L. Biometrical genetics. 3. ed. London: Chapman and Hall, 1982. 396 p.

RECOMENDAÇÕES técnicas para a cultura do milho no Estado do Rio Grande do Sul. Porto Alegre: Fepagro/ Emater-RS/Fecotrigo, 1998. 148 p.

REIS, E. M.; CASA, R. T. Manual de identificação de moléstias em milho. Passo Fundo: Aldeia Norte, 1996. 80 p.

RITCHIE, S. W.; HANWAY, J. J.; BENSON, G. O. Corn grows. Disponível em: <http://www.ag.aistate.edu/ departments/agronomy/corngrows.html>. Acesso em: 22 set. 1999.

SAWAZAKI, E.; DUDIENAS, C.; PATERNIANI, M. E. A. G. Z.; GALVÃO, J. C. C.; CASTRO, J. L.; PEREIRA, J. Reação de cultivares de milho à mancha de Phaeosphaeria no Estado de São Paulo. Pesquisa Agropecuária Brasileira, Brasília, v. 32, n. 6, p. 585-589, jun. 1997.

VASAL, S. K.; SRINIVASAN, G.; CROSSA J.; BECK, D. L. Heterosis and combining ability of CIMMIT's subtropical and temperate early-maturity maize germplasm. Crop Science, Madison, v. 32, p. 884-890, 1992. 